\title{
A plea for teaching writing as an integrative process meant to serve a functional purpose
}

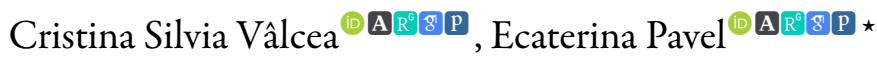 \\ Faculty of Letters, "Transilvania” University of Brașov, Bd. Eroilor 29, 500036 Brașov, Romania
}

\section{Article info \\ History: \\ Received September 18, 2021 \\ Accepted October 20, 2021 \\ Published December 12, 2021}

Key words:

writing

writing process

writing product

school curriculum

functional illiteracy

\begin{abstract}
In the Romanian context, writing is in a paradoxical situation: it is claimed to be important though it is one of the skills that is little invested in and moreover it undergoes strong opposition from the parents who would opt for digitalization as a preventive opportunity for their children in the future. Mistreated by both school and society, writing is given meagre chances of proving its determining role in the intellectual formation of the young generation. In this line of thought this paper aims at mapping writing as a school-taught skill by first outlining the Romanian approach to school writing (as product or process) and secondly by carrying out an analysis of the writing tasks regularly assigned, with a view to emphasizing their ups and downs and to suggesting changes that might improve not only the perception on writing in the Romanian curriculum, but also the quality of the educational output. In order to obtain a good representation of how writing is viewed by the Romanian educational system, it is deemed as appropriate to analyse the school curriculum issued and approved by the Ministry of National Education and to evaluate the implementation of the official guidelines into school textbooks. The justification for the interest of the authors in writing is related to the high rates of functional illiteracy, to the preponderant evaluation type of the pupils (a written one) and to the largely acknowledged inability of pupils to successfully manage their written tasks.
\end{abstract}

\section{Introduction}

Writing and especially handwriting seem to be intrinsically associated with old-fashioned education systems that need to be disrupted by means of new forms of pedagogy and technical resources. The Romanian education system has been facing fundamental problems affecting the teaching / learning process of writing in primary school and, later, in secondary and higher education. From a wider, overall perspective, the main challenges are the ever-changing educational reforms, the lack of material and human resources, the high rates of school abandonment, the low attractiveness of the teaching profession and demotivating salaries, the shortage of staff with proper qualifications in rural and remote areas, the weak funding programmes to support equity (European Commission, Education and Training Monitor 2019. Romania, p. 5-9). Analysed from the narrower perspective of the beneficiary, challenges range from the lack of personal motivation (education does not seem anymore a desideratum or the path to success), the lack of pleasure (pupils/students spend many hours in class, learning mostly theoretical notions which they fail to use in connection with other inter- and trans-disciplinary concepts), the dense curricula, insufficiently adapted to the age levels, and the punitive methods still widely used (low grades, verbally cornering students) which lead to an even greater learner demotivation.

Disparities between rural and urban areas remain prevalent. On the one hand, disadvantaged categories are concentrated in rural areas, where difficult conditions and rudimentary methods persist due to the lack of necessary funds. Children face early school dropout, difficult commutes, or various crises caused by

^Email addresses: cristina.valcea@unitbv.ro (CSV), ecaterina.pavel@unitbv.ro(EP). 
their parents' migration towork abroad (neglect, abuse, anxiety, depression, deviance, delinquency). Low literacy is always linked to the financial, psychosocial or behavioural issues of the disadvantaged regions; however, literacy is the only chance to fight and escape poverty and extreme poverty. It is a knowledge gap that needs to be overcome in order to interrupt the vicious circle of illiteracy that generates poverty and of poverty that leads to functional illiteracy.

On the other hand, in urban areas, schools seem to turn more and more towards digitalisation, to the detriment of handwriting. But digital skills do not necessarily mean more functional literacy. A recent study estimates that in the EU, Romania ranks second in terms of functional illiteracy, with $44 \%$ of young people under 15 being unable to perform satisfactorily in reading, mathematics and science (OECD, PISA 2018 Results). In primary school, immediately after achieving basic literacy, the functionally illiterate pupils might read a text failing to understand its message; they may be able to retain the information and reproduce it well, without having the ability to use it in real life or without making connections with other acquired notions; they may write with difficulty and express themselves in writing without much coherence. Beyond the reasons mentioned above, it is to be analysed whether the school curriculum contributes or not to more or less subtle forms of functional illiteracy. An aspect that will be explored later in this article.

\section{Writing as process}

Success has been traditionally linked to good writing skills and "a basic aim of schooling is to teach students to become competent writers". But what does "competent writers" (Graham, 2019, p. 278) mean in the Romanian education system? Our paper aims to produce a relevant analysis below.

\subsection{Handwriting or typing?}

The first question that arises is, predictably: why should pupils study cursive writing when classes, homework, activities and even exams tend to go online? When children, from an early age, are engaged with technology rather than traditional games and activities? Despite these objections, handwriting should not be dismissed, and researchers are advocating for it. Through cursive writing, we cognitively assimilate knowledge and communicate ourselves. Handwriting allows that time to think, to reflect on the structure, correctness and choice of words. In addition, although we live in a digital age, organising speech, taking notes, summarizing, arguing can be better achieved through handwriting in the early stages, since it provides the neural stimulation necessary for cerebral development. "Handwriting is more than a simple fine motor task; it requires performance in perceptual-motor skills, motor planning, visual perception, visual-motor integration, bilateral hand skills, in-hand manipulation, kinæsthesia, sustained attention, sensory processing, and the presence of proper biomechanical components for posture and hand grip" (Lust \& Donica, 2011, p. 560). Moreover, better handwriting is linked to greater neural activation in areas associated with long-term memory and working memory (Berninger et al., 2006, p. 84) and it "may contribute to treating reading disabilities and possibly to normal reading development" (Berninger et al., 2006, p. 67).

The discussion is not necessarily about cursive writing, but about the sheer act of handwriting, which seems to be soon replaced by typing. On the one hand, we could argue in favour of typing, if we take into consideration that it involves the coordination of both hands and, therefore, produces a better connection between the cerebral hemispheres. But, on the other hand, handwriting occurs mainly by using the right hand, controlled by the left hemisphere, specialised for processing language functions and producing speech. From the point of view of neuroscience, the brain functions distinctively when engaged in typing, but we lack yet the experience to say whether this change is a positive, negative or neutral one. As adults who learnt handwriting and used it extensively, switching to typing at the expense of handwriting had no significant effects on our brain activity. But synaptic pruning and neural connections development in children who learn to use typing predominantly can profoundly affect cognitive abilities. Handwriting helps our visual memory, by recollecting a gesture and the shape of a letter made by that gesture. In her 
study, Karin James showed how children who learnt the alphabet by handwriting recognise the letters more easily, which helps them read faster and more fluently. And reading, in turn, is important for school success: "handwriting experience plays a crucial role in the formation of the brain network that underlies letter recognition" and it is important "for letter understanding and therefore for literacy development. [...] The motor system creates variability (through handwriting in this case) in our perceptual world that enhances behavioural performance and serves to link brain systems into functional networks" (James, 2017, p. 507).

Digital tools tend to become obsolete faster than pens and paper. So, while it may be true that electronic writing is widely used today, we don't know what tomorrow's keyboards will look like. We should remember that a few years ago, phone keys were used differently than they are todayand that some of today's keyboards are moving towards a sliding motion to write, only lifting the finger between words. Therefore, we might consider that it is preferable to learn the basics of writing in a traditional manner, independently of electronic tools, because they can be transferred and used in any circumstance. In addition, extensive access to electronic resources tends to predispose students to laziness: they no longer take notes, but pictures: they simply prefer to photograph the blackboard or flipchart. Or they record their teacher explaining the lesson, and these recordings remain stored and unused, but they give students the impression that they have made the minimum effort to participate in class. Moreover, when it comes to typing and the passivity it may bring about, we cannot help but notice that the AutoCorrect feature does not help much in mastering a language and its grammar or orthographic rules. This function alters our vigilance and ability to detect and correct our own errors.

\subsection{Formal aspects of writing}

Before debating about writing as a product, we need to focus on the process of writing. Obviously, in primary school, the emphasis is placed on the structural aspects, which are at the core of writing activities (or at least they should be): calligraphy, spelling, diacritics, hyphenation, punctuation, and so on. For this reason, cursive writing and dictation used to be standard curricula during the first and second grade and the recent decision to eliminate them can appear rather inexplicable. Cursive writing, dictation and reading classes have been replaced by a problematic hybrid called "Communication in the Romanian language", which no longer comprises solely cursive writing, reading or verbal communication, but a little and none of all at the same time, which is not particularly helpful for young brains' organisation. Of note, a peculiar feature of the $1^{\text {st }}$ grade textbook is that it abounds, from the very beginning, in complex statements and requirements addressed to the student who does not yet know how to write or read. Then, from time to time, under the heading "We write beautifully!" a calligraphic sentence appears, and students are urged to produce beautiful handwriting too. The problem is that cursive writing requires hours of practice, so for the pupils in primary school it remains an abstract notion, given its elimination from the curriculum. This can lead to frustration and decreased self-confidence. With the focus shifting on disparate skills, educators can only attempt to teach legible writing and reading proficiency, but with questionable success.

Another aspect which may need reforming or improving is the teaching of spelling. For example, the difference between hyphenated and nonhyphenated morphemes (s-au/sau, i-au/iau, etc.) - they are briefly reviewed every year, which would be beneficial if the curriculum were not so dense, and the children did not forget most of the syllabus as they move forward in their academics. Additionally, the correct spelling with $\hat{\imath} / \hat{a}$ is also taught from the $1^{\text {st }}$ grade. The difference, in itself, is a linguistic nonsense, but this is beyond the scope of this paper. However, using two graphemes for the same phoneme in a phonetic language, depending on their place (in the middle/at the beginning or end of a word) tends to be quite perplexing and confusion increases as the pupil finds out that this rule changes in the case of compound or derived words. Derivation could be difficult to explain in primary school, and the rule itself is confusing among adults, not just children with limited abstract thinking skills. Another example refers to the importance of handwriting in relation to diacritics. That is because online writing tends to "omit" diacritics: speakers may pronounce a word in one way and write it completely differently (which is unsuitable for a 
phonetic language). On the one hand, this can be confusing ("tară” - hereditary defect is different from "țară" - country; "sârmă" - wire from "sarma" - cabbage roll), and on the other hand, we have encountered students who do not even use diacritical marks in handwriting.

Nevertheless, the elimination of the cursive writing and dictation classes is "compensated" by the fact that later, for disciplines such as history, biology, geography, etc., teachers greatly rely on dictation, still used to transmit course content to students. Which, in the $21^{\text {st }}$ century, proves to be counterproductive: first, course content could be easily available on any kind of support and focus should shift from writing and learning theory by heart to understanding and making connections. And second, even if the handwriting average is, in theory, satisfactory, it still remains an average between two extremes (the insufficient practice of handwriting in appropriate contexts versus its excessive, inefficient use which does not stimulate proper assimilation, creativity, applicability). All these shortcomings are accentuated by the assessment process which requires faithful rendering of the dictated information. Even in subjects where critical thinking, imagination and interpretation should exist (communication and literature classes) freedom of opinion is not encouraged-in secondary and higher education, students memorise patterns by which they must prove that a work belongs to a certain genre (lyrical, epic or dramatic), they learn by heart characterisations or information about a literary work, often without reading or understanding the work itself, because assessment frameworks encourage this type of information "cloning". Any attempt to step out of these rigid boundaries can lead to a low grade, so students line up in this army of scribes and copiers. Additionally, the use of technology makes students more susceptible to plagiarism, especially when they lack the practice of distinguishing between literally reproducing information and freely rendering assimilated knowledge. It is also the uncritical use of technology that hinders students' ability to distinguish between formal and informal language, causing them to use familiar or even colloquial structures in formal papers, which brings us to the more complex aspect of writing.

\section{Writing as product}

Writing is highly valorised due to the great impact it has on mental development and health (Pizarro, 2004 , p. 5-12) by the fact it eases stress and increases sociability and on school success (Espin et al., 2008, p. 174-193) measured in standard tests. The writing's impact on school children psychic and achievement doubled by its primordiality in the workplace has given writing the importance that school has a great difficulty to live up to. This fact is largely acknowledged by researchers who identify either mechanical problems, such as spelling, punctuation, and handwriting or system problems among which teachers' reluctance to teach writing (Draper, 2002, p. 357-384) and students' linguistic and cognitive issues (Kellogg \& Raulerson, 2007, p. 237-242) that make writing difficult.

The difficulty that is claimed to hinder more and better writing practice may result from the complexity of writing which has been defined as "a vital component of students' literacy achievement, and [...] a critical communication tool for students to convey thoughts and opinions, describe ideas and events, and analyse information. Indeed, writing is a life-long skill that plays a key role in postsecondary success across academic and vocational disciplines" (Institute of Education Sciences, 2016, p. 1). Other definitions focus on the idea of purpose which highlights the intention and motivation that should underlie all writing tasks: "[writing is] encoding and composing meaning into written text in order to achieve particular purposes" (Harris \& Chapman, 2004, p. 417-431).

The complexity is further epitomised by the metalinguistic (rhetorical organisation) and metacognitive (appropriate language use, specific language, lexical and syntactic knowledge) skills that demonstrate learner's acquired awareness in the writing process. Since learning writing is gradual, all these perspectives on writing indicate actual stages in writing learning from primary school to professional and academic writing. A valuable argument for the necessity of teaching writing due to its complexity is the one provided by Kellogg (2008, p. 2) who claims that writing is wrongly assumed as innate to humans as speaking is: "Learning how to compose an effective extended text, therefore, should be conceived as a task similar to 
acquiring expertise in related culturally acquired domains. It is not merely an extension of our apparent biological predisposition to acquire spoken language."

As the development of the skill of writing is gradual, the Romanian educational system takes on a similar gradual introduction of the writing elements. All findings are based on the national curriculum issued and approved by the minister of education.

\begin{tabular}{l|l} 
6-7 year old & $\begin{array}{l}\text { writing begins by recognising and naming the letters and by } \\
\text { developing writing-bound muscles. }\end{array}$ \\
\hline $7-8$ year old & $\begin{array}{l}\text { handwritten letters, first copied written products: tickets, invitations, } \\
\text { cards with a focus on layout, letter and syllable dictation, posters. }\end{array}$ \\
\hline $8-9$ year old & $\begin{array}{l}\text { copying and transcribing letters, syllables, words, sentences with a } \\
\text { focus on layout, posters. }\end{array}$
\end{tabular}

\section{Developing writing skills in the Romanian primary school system}

Product-based writing consists basically of the imitation of a model that is studied in terms of the component elements, technicalities, and layout to the end of reproducing both content and structure. There is little space for innovation or creativity as the main purpose of this type of writing is to get students accustomed to writing pattern documents: e-mails, reports, invitations, postcards, letters, etc., which is preferable in this case. In other words, it is about learning the forms which will permit expression (Davies, 1988, p. 130-142). It is highly imitative and fails to get students involved in the production of the text given the prescriptive nature of the documents. Badger \& White (2000, p. 153-160) maintain that in the product-based approach, language gets the upper hand as what is assessed is the grammatical accuracy of the production. Writing comes second or represents the excuse for assigning the task. Moreover, writing in general gets reduced attention as it is considered less important than oral communication. The gain of the students lies in the knowledge they acquire about how to produce such a patterntext. The accent is on the final product and on the analysis of the model that must be imitated.

Process-based writing has appeared as a reaction to product-based writing in an attempt to give students more freedom when expressing their ideas. The stages before actual writing are given great importance as brainstorming and planning prove their efficiency when carrying out writing. After-writing stages are equally important since revising, correcting and improving are part of the process of writing. External interventions of various natures, either teacher or mate-provided, are believed to be beneficial for students as they add more reflexiveness to the piece of writing. Feedback is therefore essential to the process-based writing approach as it provides hints at how the text could further develop to the benefit of the student. Yet, if there is something that the process-based writing approach has contributed withis definitely the development of a sense of audience, which transforms writing from a useless, good-for-nobody-to-read item into a piece that might get some audience which impacts writing under the aspect of credibility, of real-to-life explanations that might get an answer to. Boughey $(1997$, p. 127) stresses that "the need to pay attention to the audience of the text prompts writers into anticipating and considering viewpoints other than their own. The result of this is that propositions contained in the content of the text are likely to be more rigorously scrutinised than if they were simply thought about".

The poor school performance in writing of Romanian pupils is by far a singular case. Research claims a generalisation of writing problems as a symptom of an educational system that lacks time to invest in pupils' writing. As a fact, writing does presuppose a great time and effort investment (Berman \& Cheng, 2010, p. 25-40) in order to become an effective skill capable of offering pupils the advantages of being fully trained in writing. Yet, the Romanian educational system approaches writing as a product which is produced on the spot as any grammar or vocabulary exercise. As an illustration of the writing tasks that are predominant in the Romanian educational system, we analyse the writing tasks in Romanian textbooks for the first and second grades that are approved by the Ministry of Education in Romania. In doing that, 
our intention is to analyse the way/s in which Romanian textbooks teach writing to very young pupils and how the bases of writing are laid. The elements that are of interest for our research are: the formulation of the writing task with a focus on clarity and complexity, the preparation of the writing task or scaffolding (pre-writing tasks, vocabulary focus, grammatical structures to be used), brainstorming and selecting the best ideas to be included in writing. Although the writing process usually continues beyond the before mentioned stages with successive drafting, teacher evaluation and feedback and rewriting upon teacher instructions, our research is limited to textbook writing tasks as our interest is with the identification of the state-accepted writing policy for the pupils in the primary classes. Teacher evaluation and feedback can hardly be categorised as unitary and largely generated as a state policy, although these aspects should undergo transformation in the direction of standardisation and importance increase.

\section{Findings and discussions}

After the selection of the writing tasks from two textbooks for the first and second grade, the tasks were organised into categories as it became clear that the tasks follow some repetitive patterns throughout the book. Thus, the majority of the writing tasks ask pupils to identify certain types of words in the texts they study (words that contain a certain letter or that begin with a certain letter) which afterwards they have to introduce in sentences of their own. Another type of task asks pupils to make up sentences in order to include certain words in them. At times, pupils are asked to write freer pieces of textwhere they need to write on a certain topic without being imposed to use certain words or expressions (write about the books' role in people's lives, describe your grandmother/grandfather). A task that is quite frequent asks pupils to transcribe, that is, to copy certain words from the text or parts of the text. At a first analysis, it can be concluded that the writing tasks are of three types: non-productive (e.g. transcribe), semi-productive (e.g. write sentences that should contain ...) and productive (e.g. write a description of ..., write about the role of ...). The instructions for all writing tasks are short, indicating exactly the outcome that the pupils are expected to produce. In some tasks the focus is on writing as a technical ability to write words or sentences, whereas in others writing is dealt with as a skill that implies writing on a topic while observing vocabulary and grammar rules and organisational patterns.

Types of task:

- Write one sentence that should contain the following words.

- Write, by selecting from the text one word that should contain each of the following letters in initial position.

- Write an utterance about the first school day in your life.

- Make up sentences of your own where each word should begin with the same letter.

- Write an utterance about the role of books in humans' lives.

- Accompany the drawing with a few suggestive utterances.

- Transcribe the words underlined in the text.

- Write a description of your grandmother / grandfather.

A first observation that is worth bringing into discussion is the type of writing that the Romanian school teaches by the books that it produces and uses. Although it may be claimed that the type of writing may not be naturally deduced on the basis of the tasks, it is quite easy to demonstrate that the way the task is formulated greatly impacts the success or failure of the writing task. Thus, in order to actively participate in the tasks, pupils need to feel motivated to work on that task which motivation may be given by the task which is clear, well-supported by arguments and the pupils understand the reason for working on it and they equally grasp the outcome of their efforts (Ellis, 2003, p. 57-63). Moreover, Lee (1999, p. 77) considers that the more organised and clearer the task, the better the results that the pupils will obtain. The short formulation of the tasks is not necessarily to the student's advantage given their age. On the contrary, 
the task should be as long as it takes in order to clarify the steps on the one hand and to motivate the pupils on the other hand. Dörnyei (2001, p. 120) argues in favour of the explanation of the 'purpose and utility' of the task. From this point of view the Romanian textbooks that have been analysed in terms of writing tasks have completely failed to present the purpose and the utility to the pupils. It is not that there is no purpose or utility, it is that by not presenting it clearly to the target audience, they may misunderstand it or find it useless. Yet, we are fully aware of the fact that it is theteacher's role to adapt the material in the textbook and to help pupils understand a task in terms of purpose and utility, but it goes without saying that textbook authors and authorities have the role to produce materials that encourage education and aim at improving pupils' writing skills.

Moreover, when new types of tasks are introduced, it is highly recommended that examples or models should be provided so that the pupils understand what is expected of them or what they should do. An additional advantage of providing a model is the difficulty which Skehan (1996) defines as 'cognitive load' that pupils experiment when exposed to a new task. The textbooks that have been analysed have not provided any model or example for the regular writing tasks. Yet, models are provided when it comes to the pattern that should be observed when copying a text or a poem into the notebook. The exact location of the data, title, and author are strictly indicated by the help of a handwritten model existent in the textbook. It is true that the correct use of data, title and author may contribute to the æsthetic aspect of the writing, but it can hardly improve the pupils' real writing skills. To exemplify, the textbook instructs pupils on what they are expected to do and advises them to 'write the text, observing the orthography and punctuation rules and the page layout'. This is yet another proof of the fact that writing for the authors of these textbooks is a technicality which relies on external elements and not on internal and intrinsic elements to writing.

The organisation of tasks into three-fold stages is beneficial for both pupils and teachers. The pupils benefit from the three-fold organisation by the fact that they are introduced in a preliminary task called 'pre-task' which is meant to help them understand, practice, structure and draft for the next stage. The pre-task is an opportunity to incorporate new information into pre-existing knowledge, which proves its usefulness in the great picture of writing teaching and learning. The 'during-task' is the time when pupils are actually producing content in accordance to the input they have been exposed to in the 'pre-task' stage. The last stage named 'post-task' is viewed as a follow-up which enhances comprehension, experience and exposes pupils to further practice. As writing is complex and found difficult by both pupils and teachers, it is the more necessary to prepare writing tasks to the smallest details that might help students improve their writing. For most writing tasks in the textbooks under analysis there is no 'pre-task', which means that pupils write straightforwardly without any previous introduction into the topic. The textbooks under scrutiny stand out by their reduced or inexistent preparation of writing. No vocabulary appropriate for the topic of the writing task, no grammar rule that might be predominant in that type of writing, no previous brainstorming of ideas that might be included, no responsibility instilled in children as far as deciding what to introduce and what to leave out is concerned, no teaching of writing as an activity that is addressed to some real readers have transformed writing into a burden that Romanian pupils grapple with ineffectively. The absence of the pupils training for the idea of audience is significant for the little importance that writing, as a real product of pupils' efforts, is paid. The inability of the educational system to create an educational background likely to simulate real-life situations results in pupils' weak performances in writing.

When writing is guided, though those cases are quite rare, the indications in the textbook are mere impositions that tell you what to do, not how to do it. Second grade pupils are asked to write a free composition based on some images and they are instructed to first write sentences about each image and then they are asked to enrich the sentences by adding 'special expressions'. Firstly, it is worth noticing that the task suggests there should be successive stages in the writing of the free composition by requiring that the sentences should be enriched, although that is not openly stated. Interestingly enough, the 'special expressions' are not given, and pupils are expected to know and introduce them, each of them depending 
on their own knowledge of 'special expressions'. The quasi-guiding is prescriptive and highly devoid of real educational value that might help pupils discover writing. Another writing task that is frequently used in the Romanian textbooks is the diary which supposedly encourages the pupils' practice of a free type of writing. Nevertheless, consideringthe fact that writing is not spontaneous, even free writing should be taught and learnt. Moreover, the diary is a literary species that, though personal, has a confessing character which, for accuracy and conformity, should be written in a specific style.

Another puzzling aspect of the analysed textbooks is the language of the studied texts and, sometimes, of the requirements themselves: oftentimes, children have to study texts with archaic or obsolete language, very unnatural and far from the vocabulary used by children aged 7-8 years (for example, $19^{\text {th }}$ century poems, which present difficulties not only at a lexical level, but also syntactically). Furthermore, the object itself of some requirements is problematic. For example, second graders are asked to "write two reasons that justify" an outdated proverb: cartea este o comoară de învățătură ("the book is a treasure of erudition"). First, the obsolete formulation of the proverb generates age-related understanding challenges. Secondly, the children must automatically agree (they must justify the statement, so they are not allowed to have a different opinion), which raises questions about the relation between writing and critical thinking. And thirdly, they are not provided with a structure and examples of argumentative texts or sentences.

Going back to the matter of successful writing, Graham (2019) states that a solid writing programme is primarily conditioned by the endeavour of teachers committing "a considerable amount of time to teaching writing' - a luxury that Romanian teachers cannot afford, due to the time required for additional administrative and bureaucratic work they need to do. When analysing successful strategies, Graham noticed a fundamental constant: "teachers commonly made a variety of adaptations for struggling writers in their class". A key strategy difficult to use in Romania, due to two factors: first, it is hard to manage classes of 30 students and pay attention to each and every one of them, with a focus on the slow learners. And second, it is also hard (although imperative) to break the tradition of simply "punishing" the struggling students.

\section{Conclusions}

In their majority, public statements and reforms adopted in Romanian school education have emphasised the important role of writing skills in the learning process. However, writing seen both as a traditional process and as a product has faced resistance and has also undergone various transformations with questionable results. Such transformations and results were analysed in the present article, with a focus on writing in primary school, first and second grade.

It may be claimed that writing can hardly be taught in the first part of the primary school and that children cannot understand complex and complicated terms about writing, which is completely true. Yet, writing in primary school is not about concepts or about performance. It is about a plea for the importance of writing that pupils need to be aware of, it is about learning the power of words when combining them, it is about a continuous encouragement of pupils to express their thoughts, it is about the teachers' permanent efforts to popularise writing among pupils as a means of proper communication equally important to oral communication. It is, or it should be. And it is, at the deepest level, a matter of fundamentally reforming the Romanian education system starting with the teachers' training, with the textbooks, and with the effective use of the human and financial resources. Policy makers should, therefore, put education at the forefront of their agenda and question their theories about what makes a good school. A school which does not widen inequality and produces functional illiteracy. A school designed to educate every child.

\section{Bibliography}

\section{A. Sources}

European Commission (2019). Education and Training Monitor 2019. Romania, [online]. 
Institute of Education Sciences (2016). Teaching Secondary Students to Write Effectively, [online].

OECD (2019). PISA 2018 Results. Volume I: What Students Know and Can Do, OECD Publishing, Paris, [online].

\section{B. Reference works}

Badger, R. \& White, G. (2000). A process genre approach to teaching writing, in “ELT Journal”, 54 (2), p. 153-160, Crossref.

Berman, R. \& Cheng, L. (2010). English academic language skills: perceived difficulties by undergraduate and graduate students, and their academic achievement, in "Canadian Journal of Applied Linguistics", 4 (1-2), p. 25-40, [online].

Berninger, V., Abbott, R., Jones, J., Wolf, B., Gould, L., Anderson-Youngstrom, M., Shimada, S. \& Apel, K. (2006). Early Development of Language by Hand: Composing, Reading, Listening, and Speaking Connections; Three Letter-Writing Modes; and Fast Mapping in Spelling, in "Developmental Neuropsychology", 29 (1), p. 61-92, Crossref.

Boughey, C. (1997). Learning to write by writing to learn: A group-work approach, in "ELT Journal", 51 (2), p. 126-134, Crossref.

Bromley, H. (2006). Making my own mark - Play and writing, Early Education, London.

Davies, F. (1988). Designing a writing syllabus in English for Academic Purposes: process and product, in Robinson, P. (ed.), Academic Writing: Process and Product, Modern English Publications, London / Hong Kong, p. 130-142.

Dörnyei, Z. (2001). Motivational Strategies in the Language Classroom, Cambridge University Press, Cambridge, Crossref.

Draper, R. (2002). Every Teacher a Literacy Teacher? An Analysis of the Literacy-related Messages in Secondary Methods Textbooks, in "Journal of Literacy Research", 34 (3), p. 357-384, Crossref.

Ellis, R. (2003). Task-based Language Learning and Teaching, Oxford University Press, London.

Espin, C., Wallace, T., Campbell, H., Lembke, E., Long, J. \& Ticha, R. (2008). Curriculum-Based Measurement in Writing: Predicting the Success of High-School Students on State Standards Tests, in "Exceptional children", 74 (2), p. 174-193, Crossref.

Graham, S. (2019). Changing How Writing Is Taught, in "Review of Research in Education", 43 (1), p. 277-303, Crossref.

Harris, A. \& Chapman, C. (2004). Improving schools in Difficult Contexts: Towards a Differentiated Approach, in "British Journal of Educational Studies", 52 (4), p. 417-431, Crossref.

James, K. (2017). The Importance of Handwriting Experience on the Development of the Literate Brain, in "Current Directions in Psychological Science", 26 (6), p. 502-508, Crossref.

Kellogg, R. (2008). Training writing skills: A cognitive development perspective, in “Journal of Writing Research", 1 (1), p. 1-26, Crossref.

Kellogg, R. \& Raulerson, B. (2007). Improving the writing skills of college students, in "Psychonomic Bulletin \& Review", 14, p. 237-242, Crossref.

Lee, J. (1999). Tasks and Communicating in Language Classrooms, McGraw-Hill Humanities, New York.

Lust, C. \& Donica, D.(2011). Effectiveness of a Handwriting Readiness Program in Head Start: A Two-group Controlled Trial, in "American Journal of Occupational Therapy", 65 (5), p. 560-568, Crossref.

Mihăilescu, C. \& Pițilă, T. (2018). Comunicare in limba română: manual pentru clasa a II-a, Editura didactică și pedagogică, București.

Pizarro, J. (2004). The Efficacy of Art and Writing Therapy: Increasing Positive Mental Health Outcomes and Participant Retention After Exposure to Traumatic Experience, in "Art Therapy", 21 (1), p. 5-12, Crossref.

Skehan, P. (1996). A framework for the implementation of task-based instruction, in "Applied Linguistics", 17 (1), p. 38-62, Crossref. 